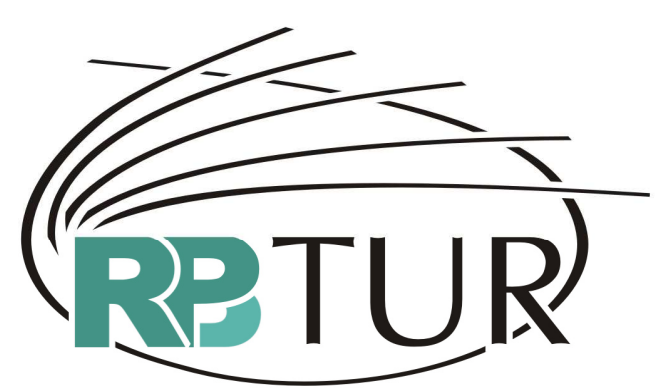

REVISTA BRASILEIRA DE PESQUISA EM TURISMO

\title{
THE (IN) DISCIPLINE OF TOURISM RESENHA DE LIVRO
}

Margarita Barretto ${ }^{1}$

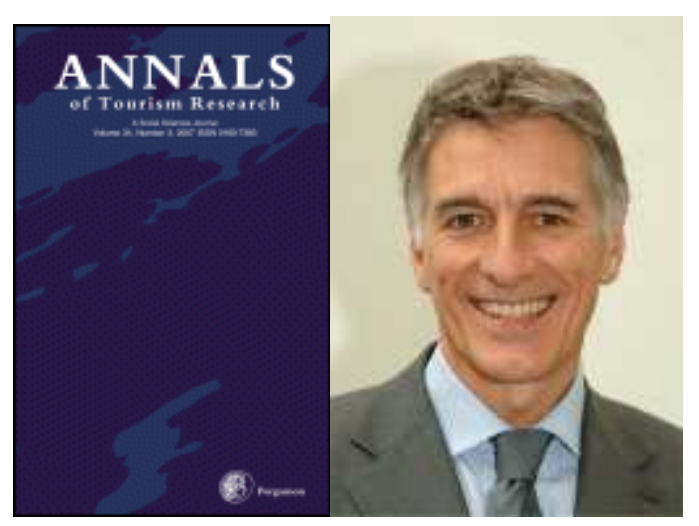

TRIBE, John. The (in) discipline of tourism. Annals of Tourism Research, v. 24, n. 3, p. 638-657, 1997.

John Tribe é Doutor em Economia e trabalha na Universidade de Surrey, Inglaterra. É também o presidente da Associação de Educação Superior em Turismo do Reino Unido.

O artigo analisado foi escrito há dez anos e discute a epistemologia do turismo, tema sobre o qual muito pouco se tem avançado neste período. Tomando como marco teórico a filosofia e a sociologia do conhecimento, propõe um novo modelo epistemológico para compreender o turismo.

\footnotetext{
${ }^{1}$ Doutora em Educação pela Universidade de Campinas - UNICAMP. Bacharel em Turismo pela Pontifícia Universidade Católica de Campinas. Pesquisadora do CNPq.
} 
A epistemologia é o ramo da filosofia que estuda o conhecimento. Assim, a epistemologia do turismo consiste em saber qual é o caráter do conhecimento sobre turismo, as fontes deste conhecimento, a validade e confiabilidade do que pretende ser conhecimento de turismo fora do mundo do turismo, o uso de conceitos, as fronteiras e a categorização dos estudos de turismo como disciplina ou campo.

O autor afirma que, na área de turismo há dois tipos de saberes, o proposicional, que busca saber o que uma coisa é, e o saber processual, que procura saber como uma coisa se faz.

Fora esta peculiaridade, há um problema com a palavra turismo, que tem, pelo menos, três interpretações. Chama-se turismo ao fenômeno social praticado pelos turistas; também se chama turismo ao estudo deste fenômeno e, finalmente, chama-se turismo aos programas de ensino e capacitação para trabalhar atendendo os turistas.

O turismo como fenômeno apresenta aspectos econômicos, administrativos, psicológicos, sociológicos, culturais, assim como dimensões relacionadas: turistas, negócios, comunidade local, ambiente local, governo local, país emissor.

Já o estudo do fenômeno turístico é um microcosmo do turismo enquanto fenômeno social. Implica na existência de uma comunidade de pesquisadores, no registro subjetivo do conhecimento do fenômeno e a decisão sobre que partes do fenômeno são estudadas e como se elaboram os conceitos.

O turismo enquanto objeto de ensino, por sua vez implica a opção de defini-lo como ciência, disciplina ou campo. 
Uma disciplina é uma forma de estudar, de produzir conhecimento, com seus próprios conceitos, teorias e métodos de pesquisa (ex. matemática, ciências físicas, ciências humanas, história, religião, literatura, artes, filosofia). A ciência é a comprovação empírica de determinados fatos.

Um campo de estudo é um objeto a ser estudado e está constituído por várias disciplinas, chamadas para pesquisar fenômenos complexos, tais como turismo, moradia, migrações.

Tribe analisa os conceitos de disciplina de, Hirst, Toulmin, Donald, King e Bronwell. Todos estes autores coincidem em que as disciplinas caracterizam-se por ter conceitos, métodos, estrutura lógica e objetivos próprios e únicos. Também por ter uma rede tanto de conceitos quanto de pesquisadores que compartem valores.

Nenhuma destas características se observa no turismo, onde todos os conceitos trabalhados provêm de disciplinas específicas, como a economia, a geografia, etc. Tampouco há uma rede de pesquisadores que compartam valores ou conceitos, desde que a maior parte dos pesquisadores do fenômeno turístico está alocada nos departamentos específicos da disciplina a partir da qual o estudam.

Tribe coloca como exemplo os periódicos de turismo, onde identifica a abordagem dos negócios turísticos, por exemplo Tourism Management e "outros com uma agenda mais ampla", tais como Annals of Tourism Research que congregam estudos tão diversos que demonstram a não existência de estudos turísticos homogêneos, coisa que ele, por outro lado, acha normal, dizendo que "dada a amplitude do turismo, seria surpreendente que houvesse um conjunto de valores compartidos dentro da comunidade acadêmica". 
Tribe contesta a proposta de Leiper de que o estudo do turismo seja considerado uma disciplina porque o fenômeno pode ser representado por um modelo sistêmico. Um modelo é útil para mapear as dimensões do turismo, mas nem por isso constitui uma teoria.

Por outro lado, Tribe acredita que o conhecimento disciplinar não é a única forma de conhecimento possível e que seria até empobrecedor reduzir o turismo a uma disciplina, quando é um fenômeno cujo estudo requer tantas abordagens diferentes.

Tampouco acredita que a única forma de entender o turismo enquanto fenômeno seja através da ciência. Há partes do fenômeno turístico que admitem e requerem análise científica, mas há outras partes que não. Cair na cientifização pura pode levar a uma afastamento da realidade, pode levar a privilegiar o conhecimento proposicional em detrimento do processual, que é igualmente necessário.

Continuando com Hirst como base da sua análise, Tribe traz o conceito de campo de conhecimento daquele autor. Os campos se formam com o foco em fenômenos ou práticas particulares tais como turismo, ou habitação e chamam uma série de disciplinas para pesquisar. Em certo sentido, as disciplinas e os campos podem ser contrastados. As disciplinas estão unidas por uma constelação específica de teorias, conceitos e métodos enquanto que os campos se apóiam em qualquer tipo de conhecimento que possa vir a ajudar no esclarecimento do seu funcionamento. Para defender o turismo como campo de conhecimento, Tribe apóia-se em Gunn, por exemplo, que define quais as disciplinas que contribuem para o estudo do campo do turismo, embora não concorde com aquele autor quando ele afirma que há outras formas de estudo do turismo que não são científicas, como, por exemplo, a intuição, a tenacidade ou a autoridade sobre o tema. 
Tribe também valoriza o modelo proposto por Jafari e Ritchie para os estudos de turismo, mas aponta certas falhas nele, porque mistura disciplinas com objetos de estudo, por exemplo, coloca "transportes" e "parques e recreação" que são objetos de estudo no rol das disciplinas que contribuem aos estudos de turismo.

Para Tribe há - claramente - dois grandes campos sob o guarda-chuva dos estudos de turismo, um é o campo dos negócios turísticos, e o outro um campo não relacionado aos negócios, onde se incluem os impactos ambientais e sociais, as percepções etc.

Ao mesmo tempo, há conhecimento que pode ser adquirido de forma disciplinar tanto em um quanto em outro campo.

Esta complexidade leva à existência de uma zona de intercâmbio onde diferentes disciplinas dialogam, se superpõem, e onde os diferentes campos se inter-relacionam dando lugar a conceitos como o de multiplicador de turismo, que surge da aplicação das teorias econômicas ao estudo do turismo.

Por outro lado, o campo dos negócios turísticos também pode ser estudado fora da academia, com a produção de um conhecimento que Tribe chama de extra-disciplinar, que é um conhecimento gerado pelas empresas do ramo do turismo para ser aplicado nestas.

A propósito desta questão, Tribe também coloca uma preocupação com a predominância atual da tecnologia e da procura pelo desempenho, que leva a que o campo dos negócios turísticos seja privilegiado e os estudos mais humanistas, que não visam à lucratividade das empresas, sejam preteridos. "A ciência... custa dinheiro, e a tendência é favorecer o conhecimento que é útil à economia" 
O autor conclui reafirmando que os estudos turísticos não constituem uma disciplina mas dois campos de estudo e que as diferentes abordagens do fenômeno não são mutuamente excludentes, ao contrário, são complementares. Termina seu artigo com um trocadilho, dizendo que não devemos pensar na disciplina, mas na indisciplina do turismo, evidenciada na falta de agregação dos estudos referidos às questões que não envolvem os negócios turísticos, cujos estudos estão mais estruturados, justamente pelo interesse econômico que geram.

Os estudos de turismo dependem do conjunto de valores dos pesquisadores que decidem o que querem pesquisar a respeito do fenômeno. Cada disciplina fornece uma lente através da qual olhar o que ele chama de "mundo externo do turismo". Os valores predominantes em cada tipo de estudo vão fazer com que muitas vezes o mundo dos negócios turísticos não dialogue com os que estudam questões ambientais, por exemplo, e cada grupo pretenda legitimar seu saber com o seu referencial. Não havendo uma regra para julgar aplicável a ambos argumentos, a questão não pode ser resolvida de forma eqüitativa.

Outro problema apontado por Tribe é que o mundo acadêmico não considera o conhecimento produzido fora deste, no mundo empresarial, o que precisa ser superado.

Finalmente, o autor entende que o fato de que os estudos do turismo não tenham um paradigma único e que sejam da diversidade que são, é algo a ser reconhecido e até celebrado. 